Article

\title{
Graphene Ink Film Based Electrochemical Detector for Paracetamol Analysis
}

\author{
Li Fu ${ }^{1, *}$, Kefeng Xie ${ }^{2, *}$, Yuhong Zheng ${ }^{3}$, Luxi Zhang ${ }^{1}$ and Weitao Su ${ }^{1}$ \\ 1 Collage of Materials and Environmental Engineering, Hangzhou Dianzi University, \\ Hangzhou 310018, China; 161200006@hdu.edu.cn (L.Z.); suweitao@hdu.edu.cn (W.S.) \\ 2 State Key Laboratory of Plateau Ecology and Agriculture, Qinghai University, Xining 810016, China \\ 3 Institute of Botany, Jiangsu Province and Chinese Academy of Sciences, Nanjing Botanical Garden, \\ Mem. Sun Yat-Sen, Nanjing 210014,China; yuhongzhengcas@gmail.com \\ * Correspondence: fuli@hdu.edu.cn (L.F.); xiekf12@lzu.edu.cn (K.X.)
}

Received: 9 December 2017; Accepted: 25 January 2018; Published: 29 January 2018

\begin{abstract}
Graphene ink is a commercialized product in the graphene industry with promising potential application in electronic device design. However, the limitation of the graphene ink is its low electronic performance due to the ink preparation protocol. In this work, we proposed a simple post-treatment of graphene ink coating via electrochemical oxidation. The electronic conductivity of the graphene ink coating was enhanced as expected after the treatment. The proposed electrochemical oxidation treatment also exposes the defects of graphene and triggered an electrocatalytic reaction during the sensing of paracetamol (PA). The overpotential of redox is much lower than conventional PA redox potential, which is favorable for avoiding the interference species. Under optimum conditions, the graphene ink-based electrochemical sensor could linearly detect PA from 10 to 500 micro molar $(\mu \mathrm{M})$, with a limit of detection of $2.7 \mu \mathrm{M}$.
\end{abstract}

Keywords: electrode surface modification; graphene ink; paracetamol; electrochemical oxidation

\section{Introduction}

Conductive graphene ink has been commercialized and widely applied for fabricating electronic devices such as lithium battery [1,2], supercapacitor [3,4], and distributed sensor network [5-8]. Graphene ink possesses desirable properties combination, including chemical internees, environmental sustainability, and good electronic conductivity [9-18]. Compared with other solution-processed conductive inks, such as transparent conductive oxides, the abundance of graphene precursor meets sustained global consumer demands. The continuous decline of production cost of graphene showed more competitive than metal nanoparticles and nanowires based inks. The graphene also shows better competitive chemical and thermal stability than conductive polymer based inks. In order to keep the shelf life of the graphene ink, many works have been devoted using graphene oxide and its derivatives as the ink raw materials due to their well dispersibility compared with that of the graphene sheets [19-23]. Later on, exfoliated graphene sheets with different stabilizer agents also have been mixed to make stable inks [24-26]. However, these chemically modified graphene inks always suffer from the limitation of conductivity. For example, Shin et al. [27] demonstrated a graphene ink based film with thickness-dependent sheet resistance $\left(R_{\mathrm{s}}\right)$ spanning from $10^{7} \mathrm{k} \Omega / \mathrm{sq}$ before post treatment. Wang et al. [28] used Meyer rod coating to fabricate graphene ink film with $R_{\mathrm{s}}$ of 20.1 and $1.68 \mathrm{k} \Omega / \mathrm{sq}$ at $92.6 \%$ and $64.6 \%$, respectively.

Carbon-based materials have been widely used for electrode fabrication due to their excellent electric property. Graphene-based electrodes have shown superior performance in terms of electrocatalytic activity and macroscopic scale conductivity than other carbon-based materials $[29,30]$. In comparison with carbon nanotubes, graphene exhibits potential advantages of low cost, high surface 
area, ease of processing and safety [31]. Moreover, the synthesis of graphene does not require the metal catalyst, which provides a good platform to study the electrocatalytic effects of carbon materials. For example, Shuai and co-worker [32] demonstrated a graphene ink-fabricated, screen-printed electrode for sensitive determination of $\mathrm{Cd}^{2+}$ and $\mathrm{Pd}^{2+}$ in water. Secor and co-workers proposed a graphene ink-nitrocellulose electrochemical sensor for $\mathrm{H}_{2} \mathrm{O}_{2}$ determination [33]. Several works have demonstrated that a post treatment of the graphene ink could improve its conductivity through thermal reduction process [12,34,35]. More specifically, Arapov et al. [12], Secor et al. [34], and Del et al. [35] enhanced graphene ink films to sheet resistances of $1.4 \Omega / \mathrm{cm}, 21.4 \Omega / \mathrm{cm}$, and $30 \mathrm{k} \Omega / \mathrm{cm}$, respectively. However, these post-treatment methods usually need expensive instruments such as a laser.

In this work, we proposed a simple graphene ink coating post-treatment after the coating process via an electrochemical oxidation. Graphene ink has been firstly coated on a glassy carbon electrode (GCE). Then, the graphene ink modified glassy carbon electrode (GI/GCE) underwent an electrochemical oxidation process at $1 \mathrm{~V}$ vs. $\mathrm{Ag} / \mathrm{AgCl}(3 \mathrm{M})$ for additives oxidation in a phosphoric acid environment. The electric conductivity of the graphene ink was restored after the treatment due to the additives removal. Quite unexpectedly, the electrochemical oxidation process treatment exposes the surface defects of the graphene, which results in an outstanding electrocatalytic performance. Therefore, we used paracetamol (PA), a widely used antipyretic and analgesic drug, as the analyte for evaluating the electrocatalytic activity of the GI/GCE. The influence of the electrochemical oxidation parameters were studied in detail. Under optimization condition, the GI/GCE could linearly detect PA at concentration range from $10 \mu \mathrm{M}$ to $500 \mu \mathrm{M}$, with a limit of detection of $2.7 \mu \mathrm{M}$.

\section{Materials and Methods}

Graphene ink was purchased from Suzhou Hengqiu Tech Co., Ltd. (Suzhou, China), (containing 5\% graphene). Paracetamol (PA) was purchased from Sinopharm Chemical Reagent Co., Ltd. (Shanghai, China). The $0.1 \mathrm{M}$ standard phosphate buffer solutions were made from $\mathrm{K}_{2} \mathrm{HPO}_{4}$ and $\mathrm{KH}_{2} \mathrm{PO}_{4}$ by adding $1.0 \mathrm{M} \mathrm{KOH}$ aqueous solution. All reagents were of analytical grade, and Millipore Milli-Q water $(18 \mathrm{M} \Omega \mathrm{cm})$ was used throughout. All electrochemical measurements were performed using a $\mathrm{CHI} 832$ electrochemical workstation with a conventional three-electrode system comprised of platinum wire as auxiliary electrode, a $3 \mathrm{M} \mathrm{Ag} / \mathrm{AgCl}$ electrode as reference, and a graphene ink-coated glass as working electrode (digital photo of the electrochemical cell was supplied in Figure S1). A four point probe resistance meter (RTS-9, Four Probes Tech.) has been employed for measuring the sheet resistance.

A GCE ( $3 \mathrm{~mm}$ diameter) was polished with alumina-water slurry followed by thorough rinsing with ethanol and water. For the electrode surface modification, $5 \mu \mathrm{L}$ of graphene ink dispersion $(1 \%)$ was dropped onto the GCE and dried at room temperature (denoted as GI/GCE). Prior to electrochemical oxidation treatment, the modified electrode was carefully rinsed with water to remove the soluble additives, and dried in an air stream. Then, the graphene ink-modified glassy carbon electrode (GI/GCE) underwent an electrochemical oxidation process at $1 \mathrm{~V}$ vs. $\mathrm{Ag} / \mathrm{AgCl}(3 \mathrm{M})$ for additives oxidation in a phosphoric acid environment. For electrochemical oxidation process, the GI/GCE underwent a potentiostatic treatment in a $0.1 \mathrm{M} \mathrm{HNO}_{3}$. The treated GI/GCE was rinsed with water and dried at room temperature for PA determination.

For real sample analysis, paracetamol tablet was first ground to powder. Then, an adequate amount of the PA powder was weighed and dissolved into $50 \mathrm{~mL}$ water with the assistance of the sonication. Standard addition protocol has been used for calculating the recovery of the sensor.

\section{Results}

The graphene ink was firstly characterized by Raman spectroscopy. As shown in the Figure S2, the large $\mathrm{D}$ band indicates the graphene containing surface functional groups and defects; probably, some GO was added. Since the layer number estimated from Raman spectrum is also suitable for CVD prepared graphene, the $\mathrm{I}_{2 \mathrm{D}} / \mathrm{I}_{\mathrm{G}}$ ratio deduced from the spectrum only confirmed that the layer number of graphene used in this work is around 10. The electrochemical property of the GI/GCE, 
after different electrochemical oxidation times, was studied using $5 \mathrm{mM}\left[\mathrm{Fe}(\mathrm{CN})_{6}\right]^{3-/ 4-}$ in $0.1 \mathrm{M} \mathrm{KCl}$. As shown in the Figure 1A, significant difference can be observed in CV profiles of GI/GCE before and after 5 min electrochemical oxidation treatment. The current response toward $\left[\mathrm{Fe}(\mathrm{CN})_{6}\right]^{3-/ 4-}$ redox largely enhanced with a narrower peak to peak splitting, suggesting the graphene ink exhibited a superior electric conductivity after the electrochemical oxidation. We believe the electrochemical oxidation process could partially remove or destroy the stabilizer and restore the intrinsic property of the graphene ink coating. The removal of the stabilizers also increases the surface roughness of the graphene, resulting in a higher electro-active surface area for an electrochemical reaction to take place. We also observed the electronic conductivity restoration was time dependent. As shown in Figure $1 \mathrm{~A}$, the peak current continuously raises, along with the electrochemical oxidation time, from $5 \mathrm{~min}$ to $20 \mathrm{~min}$. A further increasing of treatment time shows negligible changes. Therefore, a 20 min electrochemical oxidation has been used in this work. We also measured the sheet resistance of the graphene ink coating before and after the electrochemical oxidation process. The pristine graphene ink coating exhibited a sheet resistance of $124.6 \Omega / \mathrm{cm}$. The same coating exhibited a sheet resistance of $88.6 \Omega / \mathrm{cm}$ after 20 min electrochemical oxidation, suggesting the partial restoration of electro-conductivity. The morphology of the graphene ink before and after 20 min electrochemical oxidation was observed using SEM. As shown in Figure S3, the graphene ink shows no significant morphology change except a slight increase of roughness. The stability of the graphene ink coating after treatment has been evaluated by 15 excessive scans toward $\left[\mathrm{Fe}(\mathrm{CN})_{6}\right]^{3-/ 4-}$ redox. As shown in Figure S4, the proposed GI/GCE showed good stability. The potential window of the GI/GCE has been studied as well. As shown in Figure S5, the graphene showed a stable performance from $-1.5 \mathrm{~V}$ to $1.5 \mathrm{~V}$. It is pertinent to note that the working potential plays an important role for treatment performance. As shown in Figure 1B, positive potential shift could result enhanced electronic conductivity of the graphene ink coatings. However, a decreasing of electronic conductivity was observed when the working potential larger than $1 \mathrm{~V}$. It is probably due to the graphene damage or detachment driven by a higher working potential. Therefore, working potential of $1 \mathrm{~V}$ has been chosen in this work for graphene ink treatment.
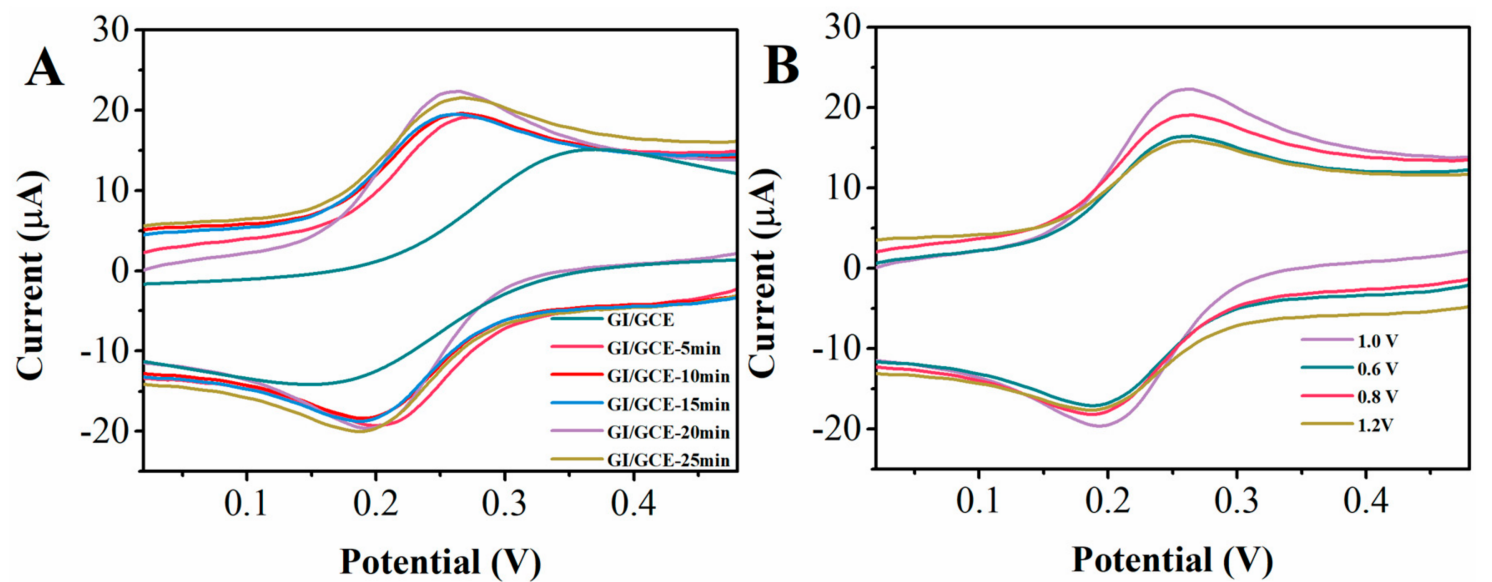

Figure 1. (A) Cyclic voltammograms of $5 \mathrm{mM}\left[\mathrm{Fe}(\mathrm{CN})_{6}\right]^{3-/ 4-}$ (in $0.1 \mathrm{M} \mathrm{KCl}$ ) at IG/GCE with different electrochemical oxidation time. (B) Cyclic voltammograms of $5 \mathrm{mM}\left[\mathrm{Fe}(\mathrm{CN})_{6}\right]^{3-/ 4-}$ (in $0.1 \mathrm{M} \mathrm{KCl}$ ) at GI/GCE with different electrochemical oxidation potential.

Due to the enhancement of the electronic conductivity, the electrochemical-oxidized graphene ink is expected to have a higher current response towards electro-active molecules. In this work, we used PA as model molecule for evaluating the sensing performance of the graphene ink after the proposed treatment. Figure 2A shows the electrochemical behavior of PA on the GI/GCE with different treatments condition. As shown in the figure, bare GCE shows an irreversible oxidation of PA during 
the CV scan. The CV profile of GI/GCE in PBS without PA showed no noticeable peaks. In contrast, it is pertinent to note that the PA redox could be observed in GI/GCE-20 min, suggesting the graphene could trigger an electrocatalytic reaction of PA molecules. More interestingly, an additional redox peak has been noticed when the graphene ink underwent a post electrochemical oxidation treatment. As shown in the figure, a pair of small redox peaks was located at $0.27 \mathrm{~V}$ and $0.21 \mathrm{~V}$, implying additional electro-redox was occurred for analyte. This redox mechanism of PA can be attributed to 1 protons and 1 electrons process (Figure 2B) due to the increases of the heterogeneous rate constant for the electron transfer. Similar phenomena were reported by other studies as well [36-38]. It is well known that the graphene used for ink preparation was usually produced using top-down exfoliation methods in order to control the cost $[39,40]$. However, the exfoliation technique inevitably introduced many defects into graphene. Although these defects affect the electronic performance of graphene, studies also noted that the outstanding activity of electrocatalysis could be produced [41-43]. Therefore, the new redox peak observed in PA sensing could be ascribed to the surface electrocatalytic sites exposure during the additives removal. A lower oxidation potential is very important for practical sensing application, because it could avoid many interference species responses at a similar working potential.
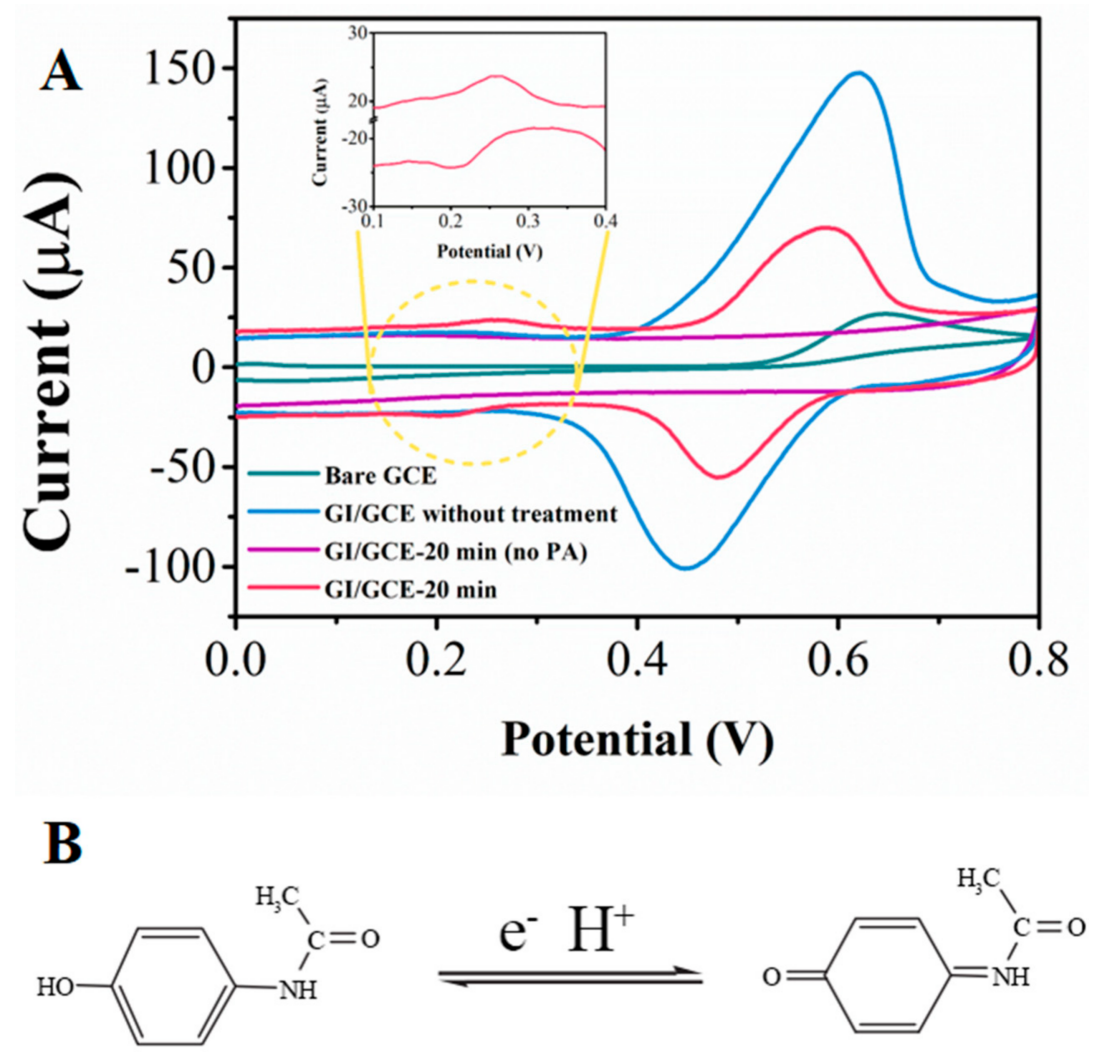

Figure 2. (A) Cyclic voltammograms of $0.2 \mathrm{mM} \mathrm{PA}$ at bare GCE and the GI/GCE with different treatment times. (B) Proposed redox reaction mechanism of PA.

We further tested the analytic performance of the GI/GCE towards PA sensing. Based on the above investigation, the GI/GCE with 20 min electrochemical oxidation was used for differential pulse voltammetry (DPV). Figure 3 shows the DPV profiles of the GI/GCE towards PA concentration from 10 to $500 \mu \mathrm{M}$. It can be seen that a linear relationship between the current response and the PA concentrations was observed in the range from 10 to $500 \mu \mathrm{M}$ with a correlation coefficient of 0.997 . The linear regression equation can be expressed as: $\mathrm{I}=29.9390+0.05442 \mathrm{C}_{(\mathrm{PA})}$. The limit of detection can be calculcated to be $2.7 \mu \mathrm{M}$ base on $\mathrm{S} / \mathrm{N}=3$. Table 1 summarized the sensing performance comparision using proposed GI/GCE with other previously reported, carbon-based electrochemical sensors. It is 
pertinent to note that the proposed GI/GCE shows a comparable sensing performance. Considering that the graphene ink was already commercialized and cheaper than other noble metal-involved electrocatalyst, this electrochemical oxidation treatment shows brightening prospects of graphene ink coatings for sensing application. Moreover, this work demonstrated other 2D material-based inks also could be applied for sensing application [44,45].

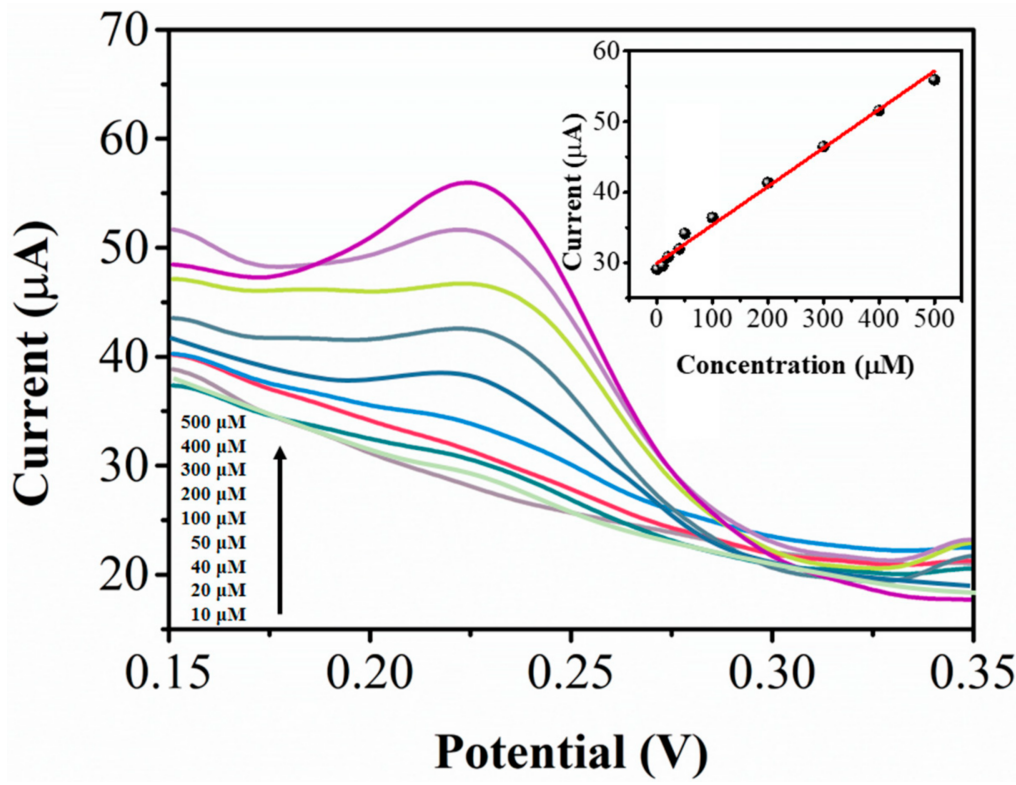

Figure 3. Differential pulse voltammograms of different concentration of PA at the GI/GCE.

Table 1. Comparison of analytical performance between GI/GCE and other carbon material modified electrodes for PA detection.

\begin{tabular}{cccc}
\hline Electrode & Linear Range $(\mu \mathbf{M})$ & Detection Limit $(\mu \mathbf{M})$ & Reference \\
\hline MWCNTs/GCE & $2-250$ & 0.16 & {$[46]$} \\
$\beta$-cyclodextrin/RGO/GCE & $10-800$ & 2.3 & {$[47]$} \\
Poly(AHNSA)/GCE & $10-125$ & 0.45 & {$[48]$} \\
RGO/CB/CS/GCE & $2.8-190$ & 0.053 & {$[49]$} \\
PDDA-graphene/GCE & $20-200$ & 0.221 & {$[50]$} \\
MWCNTs/CTS-Cu/GCE & $0.1-200$ & 0.024 & {$[51]$} \\
Nevirapine/CPE & $20-250$ & 0.77 & {$[52]$} \\
GI/GCE & $10-500$ & 2.7 & This work \\
\hline
\end{tabular}

In order to verify the practical performance of the proposed method, the GI/GCE was used for determining PA in tablet. Woolworth home brand paracetamol tablet (500 mg per tablet) was ground to powder and dissolved into water and followed by filtration for removing solid. Standard addition method was adopted for testing the recovery rate. As shown in Table 2, the detection result showed a great agreement with the value provide by manufactory. The recovery value of the GI/GCE was in the range between $99.40 \%$ and $101.48 \%$.

Table 2. Determination of PA in tablet using the proposed GI/GCE electrochemical sensor.

\begin{tabular}{cccccc}
\hline Sample & Found $(\boldsymbol{\mu M})$ & Added $(\boldsymbol{\mu M})$ & Found $(\boldsymbol{\mu M})$ & Recovery $(\%)$ & RSD $(\%)$ \\
\hline 1 & 47.89 & 50 & 97.30 & 99.40 & 3.66 \\
2 & 48.03 & 100 & 148.55 & 100.35 & 2.57 \\
3 & 47.55 & 50 & 98.99 & 101.48 & 2.29 \\
4 & 47.24 & 100 & 149.05 & 101.23 & 3.04 \\
\hline
\end{tabular}


The precision of the proposed GI/GCE electrochemical sensor was tested using a GI/GCE for continuous 8 replicate detection of $0.1 \mathrm{mM}$ PA. $4.3 \%$ current decreasing was observed in 8 th scan compared with that of the original response, suggesting good stability. For temporal stability test, we conducted 5 replicate detections of $0.1 \mathrm{mM}$ PA using a GI/GCE with $2 \mathrm{~h}$ interval. A $7.9 \%$ current decrease was observed, probably due to the graphene detachment in the drying and wetting process between each detection. The reproducibility of the GI/GCE was studied using 6 individual GI/GCEs for $0.1 \mathrm{mM}$ PA detection. An acceptable RSD of 4.5\% was found within 6 determinations. For interference study, three common species including glucose, ascorbic acid, and uric acid were tested. As shown in Figure 4, the current response of PA with the presence of 5 fold interference species shows negligible changes. Based on our previous study [48], the selectivity of the GI/GCE can be further improved by surface functionalization of beta-cyclodextrin due to its high supramolecular recognition and enrichment capability. It was also found that 20 folds of $\mathrm{K}^{+}, \mathrm{Na}^{+}, \mathrm{SO}_{4}{ }^{2-}, \mathrm{NO}_{3}{ }^{2-}$, and $\mathrm{Cl}^{-}$did not interfere in the determination, suggesting the treatment-deduced electrocatalytic oxidation of PA could effectively avoid the interference.

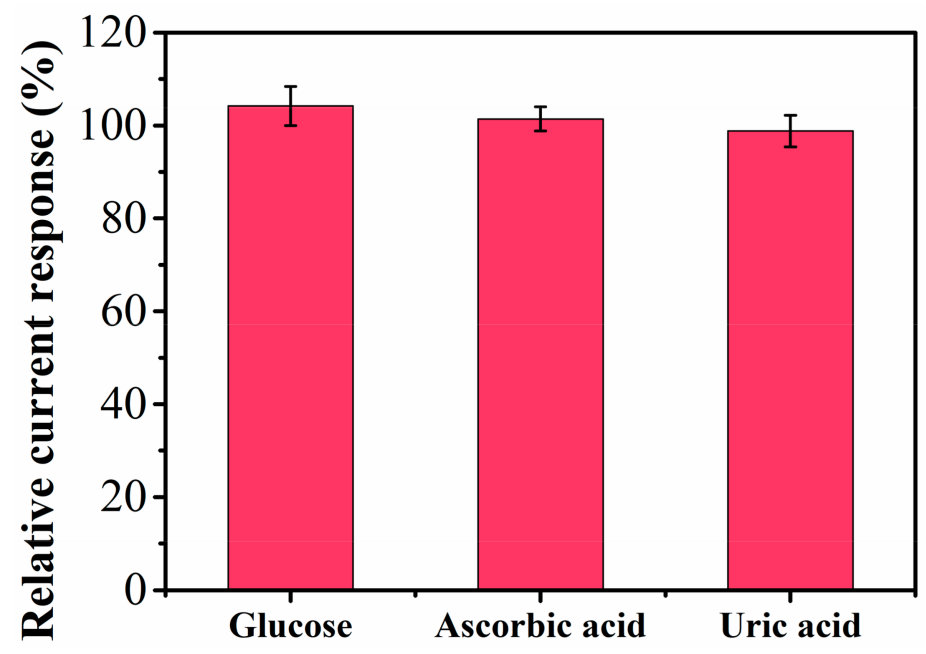

Figure 4. Relative PA oxidation current changes using the GI/GCE in the presence of interference species.

\section{Conclusions}

In this work, we proposed a simple electrochemical oxidation treatment method for restoring the electrochemical performance of the graphene ink. Due to the removal of additives and exposure of the electrocatalytic sites, the proposed GI/GCE has been successfully used for PA determination. Under optimized conditions, the proposed GI/GCE exhibits a linear PA detection range from 10 to $500 \mu \mathrm{M}$ with a detection limit of $0.27 \mu \mathrm{M}$. This simple treatment procedure extended the potential application of graphene ink. It also provides a low cost approach for sensor fabrication.

Supplementary Materials: The following are available online at http://www.mdpi.com/2079-9292/7/2/15/s1. Figure S1: Digital photo of the electrochemical cell used in this work, Figure S2: SEM images of the graphene ink (A) before and (B) after 20 min electrochemical oxidation treatment, Figure S3: Raman spectrum of graphene ink, Figure S4: 15 cyclic voltammograms of $5 \mathrm{mM}[\mathrm{Fe}(\mathrm{CN}) 6] 3-/ 4-($ in $0.1 \mathrm{M} \mathrm{KCl})$ at GI/GCE, Figure S5: Cyclic voltammograms of GI/GCE in PBS.

Acknowledgments: This work has been financially supported by Research Foundation from Hangzhou Dianzi University (KYS205617071) and Zhejiang Province Natural Science Foundation of China (LQ18E010001).

Author Contributions: Li Fu and Kefeng Xie conceived and designed the experiments; Li Fu and Kefeng Xie performed the experiments; Li Fu and Yuhong Zheng analyzed the data; Weitao Su and Luxi Zhang did the reviewer requested experiments and analyzed the data; Li Fu wrote the paper.

Conflicts of Interest: The authors declare no conflict of interest. 


\section{References}

1. Wei, D.; Andrew, P.; Yang, H.; Jiang, Y.; Li, F.; Shan, C.; Ruan, W.; Han, D.; Li, N.; Bower, C. Flexible solid state lithium batteries based on graphene inks. J. Mater. Chem. 2011, 21, 9762-9767. [CrossRef]

2. Hassoun, J.; Bonaccorso, F.; Agostini, M.; Angelucci, M.; Betti, M.G.; Cingolani, R.; Gemmi, M.; Mariani, C.; Panero, S.; Pellegrini, V. A lithium-ion battery based on a graphene nanoflakes ink anode and a lithium iron phosphate cathode. Nano Lett. 2014, 14, 4901-4906. [CrossRef] [PubMed]

3. Ervin, M.H.; Le, L.T.; Lee, W.Y. Inkjet-printed flexible graphene-based supercapacitor. Electrochim. Acta 2014, 147, 610-616. [CrossRef]

4. Xu, Y.; Schwab, M.G.; Strudwick, A.J.; Hennig, I.; Feng, X.; Wu, Z.; Müllen, K. Screen-printable thin film supercapacitor device utilizing graphene/polyaniline inks. Adv. Energy Mater. 2013, 3, 1035-1040. [CrossRef]

5. Mei, Q.; Zhang, D.Z. Photoluminescent graphene oxide ink to print sensors onto microporous membranes for versatile visualization bioassays. Angew. Chem. 2012, 124, 5700-5704. [CrossRef]

6. Radoi, A.; Dragoman, M.; Cismaru, A.; Konstantinidis, G.; Dragoman, D. Self-powered microwave devices based on graphene ink decorated with gold nanoislands. J. Appl. Phys. 2012, 112, 611-621. [CrossRef]

7. Tiwari, J.N.; Lee, W.G.; Sultan, S.; Yousuf, M.; Harzandi, A.M.; Vij, V.; Kim, K.S. High-affinity-assisted nanoscale alloys as remarkable bifunctional catalyst for alcohol oxidation and oxygen reduction reactions. ACS Nano 2017, 11, 7729-7735. [CrossRef] [PubMed]

8. Tiwari, J.N.; Kemp, K.C.; Nath, K.; Tiwari, R.N.; Nam, H.-G.; Kim, K.S. Interconnected Pt-nanodendrite/DNA/reduced-graphene-oxide hybrid showing remarkable oxygen reduction activity and stability. ACS Nano 2013, 7, 9223-9231. [CrossRef] [PubMed]

9. Wei, D.; Li, H.; Han, D.; Zhang, Q.; Niu, L.; Yang, H.; Bower, C.; Andrew, P.; Ryhänen, T. Properties of graphene inks stabilized by different functional groups. Nanotechnology 2011, 22, 245702. [CrossRef] [PubMed]

10. Mayavan, S.; Siva, T.; Sathiyanarayanan, S. Graphene ink as a corrosion inhibiting blanket for iron in an aggressive chloride environment. RSC Adv. 2013, 3, 24868-24871. [CrossRef]

11. Benwadih, M.; Aliane, A.; Jacob, S.; Bablet, J.; Coppard, R.; Chartier, I. Integration of a graphene ink as gate electrode for printed organic complementary thin-film transistors. Org. Electron. 2014, 15, 614-621. [CrossRef]

12. Arapov, K.; Bex, G.; Hendriks, R.; Rubingh, E.; Abbel, R.; De With, G.; Friedrich, H. Conductivity enhancement of binder-based graphene inks by photonic annealing and subsequent compression rolling\&thinsp. Adv. Eng. Mater. 2016, 18, 1234-1239.

13. Tiwari, J.N.; Seo, Y.-K.; Yoon, T.; Lee, W.G.; Cho, W.J.; Yousuf, M.; Harzandi, A.M.; Kang, D.-S.; Kim, K.-Y.; Suh, P.-G. Accelerated bone regeneration by two-photon photoactivated carbon nitride nanosheets. ACS Nano 2017, 11, 742-751. [CrossRef] [PubMed]

14. Le, N.H.; Seema, H.; Kemp, K.C.; Ahmed, N.; Tiwari, J.N.; Park, S.; Kim, K.S. Solution-processable conductive micro-hydrogels of nanoparticle/graphene platelets produced by reversible self-assembly and aqueous exfoliation. J. Mater. Chem. A 2013, 1, 12900-12908. [CrossRef]

15. Tiwari, J.N.; Nath, K.; Kumar, S.; Tiwari, R.N.; Kemp, K.C.; Le, N.H.; Youn, D.H.; Lee, J.S.; Kim, K.S. Stable platinum nanoclusters on genomic DNA-graphene oxide with a high oxygen reduction reaction activity. Nat. Commun. 2013, 4, 2221. [CrossRef] [PubMed]

16. Tiwari, J.N.; Vij, V.; Kemp, K.C.; Kim, K.S. Engineered carbon-nanomaterial-based electrochemical sensors for biomolecules. ACS Nano 2015, 10, 46-80. [CrossRef] [PubMed]

17. Fu, L.; Wang, A.; Lai, G.; Su, W.; Malherbe, F.; Yu, J.; Lin, C.-T.; Yu, A. Defects regulating of graphene ink for electrochemical determination of ascorbic acid, dopamine and uric acid. Talanta 2018, 180, 248-253. [CrossRef] [PubMed]

18. Fu, L.; Xie, K.; Zhang, H.; Zheng, Y.; Su, W.; Liu, Z. Multi-walled carbon nanotube-assisted electrodeposition of silver dendrite coating as a catalytic film. Coatings 2017, 7, 232. [CrossRef]

19. Guo, S.; Wang, W.; Ozkan, C.S.; Ozkan, M. Assembled graphene oxide and single-walled carbon nanotube ink for stable supercapacitors. J. Mater. Res. 2013, 28, 918-926. [CrossRef]

20. Min, J.Y.; Yoon, S.; Ji-Hoon, L.; Sung-Jun, P.; Ryong, K.S.; In, I. Submillimeter-scale graphene patterning through ink-jet printing of graphene oxide ink. Chemistry Lett. 2011, 40, 54-55. 
21. Fu, K.; Wang, Y.; Yan, C.; Yao, Y.; Chen, Y.; Dai, J.; Lacey, S.; Wang, Y.; Wan, J.; Li, T. Graphene oxide-based electrode inks for 3d-printed lithium-ion batteries. Adv. Mater. 2016, 28, 2587-2594. [CrossRef] [PubMed]

22. Tiwari, J.N.; Pan, F.-M.; Chen, T.-M.; Tiwari, R.N.; Lin, K.-L. Electrocatalytic activity of Pt nanoparticles electrodeposited on amorphous carbon-coated silicon nanocones. J. Power Sources 2010, 195, 729-735. [CrossRef]

23. Tiwari, J.N.; Tiwari, R.N.; Chang, Y.M.; Lin, K.L. A promising approach to the synthesis of 3d nanoporous graphitic carbon as a unique electrocatalyst support for methanol oxidation. ChemSusChem 2010, 3, 460-466. [CrossRef] [PubMed]

24. Parvez, K.; Wu, Z.S.; Li, R.; Liu, X.; Graf, R.; Feng, X.; Müllen, K. Exfoliation of graphite into graphene in aqueous solutions of inorganic salts. J. Am. Chem. Soc. 2014, 136, 6083-6091. [CrossRef] [PubMed]

25. Xu, S.; Xu, Q.; Wang, N.; Chen, Z.; Tian, Q.; Yang, H.; Wang, K. Reverse-micelle-induced exfoliation of graphite into graphene nanosheets with assistance of supercritical $\mathrm{CO}_{2}$. Chem. Mater. 2015, 27, 3262-3272. [CrossRef]

26. Iguchi, H.; Higashi, C.; Funasaki, Y.; Fujita, K.; Mori, A.; Nakasuga, A.; Maruyama, T. Rational and practical exfoliation of graphite using well-defined poly(3-hexylthiophene) for the preparation of conductive polymer/graphene composite. Sci. Rep. 2017, 7, 39937. [CrossRef] [PubMed]

27. Kim, K.; Ahn, S.I.; Choi, K.C. Simultaneous synthesis and patterning of graphene electrodes by reactive inkjet printing. Carbon 2014, 66, 172-177. [CrossRef]

28. Wang, L.; Deng, J.; Fei, T.; Zhang, T. Template-free synthesized hollow $\mathrm{NiO}-\mathrm{SnO}_{2}$ nanospheres with high gas-sensing performance. Sens. Actuators B Chem. 2012, 164, 90-95. [CrossRef]

29. Wang, Y.; Li, Y.; Tang, L.; Lu, J.; Li, J. Application of graphene-modified electrode for selective detection of dopamine. Electrochem. Commun. 2009, 11, 889-892. [CrossRef]

30. Alwarappan, S.; Erdem, A.; Liu, C.; Li, C.-Z. Probing the electrochemical properties of graphene nanosheets for biosensing applications. J. Phys. Chem. C 2009, 113, 8853-8857. [CrossRef]

31. Segal, M. Selling graphene by the ton. Nat. Nanotechnol. 2009, 4, 612-614. [CrossRef] [PubMed]

32. Hong, S. Graphene ink fabricated screen printed electrode for $\mathrm{Cd}^{2+}$ and $\mathrm{Pd}^{2+}$ determination in Xiangjiang river. Int. J. Electrochem. Sci. 2016, 11, 7430-7439.

33. Secor, E.B.; Gao, T.Z.; Islam, A.E.; Rao, R.; Wallace, S.G.; Zhu, J.; Putz, K.W.; Maruyama, B.; Hersam, M.C. Enhanced conductivity, adhesion, and environmental stability of printed graphene inks with nitrocellulose. Chem. Mater. 2017, 29, 2332-2340. [CrossRef]

34. Secor, E.B.; Ahn, B.Y.; Gao, T.Z.; Lewis, J.A.; Hersam, M.C. Rapid and versatile photonic annealing of graphene inks for flexible printed electronics. Adv. Mater. 2015, 27, 6683-6688. [CrossRef] [PubMed]

35. Del, S.K.; Bornemann, R.; Bablich, A.; Schäfer-Eberwein, H.; Li, J.; Kowald, T.; Östling, M.; Bolívar, P.H.; Lemme, M.C. Optimizing the optical and electrical properties of graphene ink thin films by laser-annealing. 2D Mater. 2015, 2, 011003. [CrossRef]

36. Teng, Y.; Fan, L.; Dai, Y.; Zhong, M.; Lu, X.; Kan, X. Electrochemical sensor for paracetamol recognition and detection based on catalytic and imprinted composite film. Biosens. Bioelectron. 2015, 71, 137-142. [CrossRef] [PubMed]

37. Zidan, M.; Tee, T.W.; Abdullah, A.H.; Zainal, Z.; Kheng, G.J. Electrochemical oxidation of paracetamol mediated by nanoparticles bismuth oxide modified glassy carbon electrode. Int. J. Electrochem. Sci. 2011, 6, 279-288.

38. Wei, R. Biosynthesis of Au-Ag alloy nanoparticles for sensitive electrochemical determination of paracetamol. Int. J. Electrochem. Sci. 2017, 12, 9131-9140. [CrossRef]

39. Gee, C.M.; Tseng, C.C.; Wu, F.Y.; Chang, H.P.; Li, L.J.; Hsieh, Y.P.; Lin, C.T.; Chen, J.C. Flexible transparent electrodes made of electrochemically exfoliated graphene sheets from low-cost graphite pieces. Displays 2013, 34, 315-319. [CrossRef]

40. Skaltsas, T.; Ke, X.; Bittencourt, C.; Tagmatarchis, N. Ultrasonication induces oxygenated species and defects onto exfoliated graphene. J. Phys. Chem. C 2016, 117, 23272-23278. [CrossRef]

41. Hsu, S.-C.; Cheng, H.-T.; Wu, P.-X.; Weng, C.-J.; Santiago, K.S.; Yeh, J.-M. Electrochemical sensor constructed using a carbon paste electrode modified with mesoporous silica encapsulating PANI chains decorated with GNPs for detection of ascorbic acid. Electrochim. Acta 2017, 238, 246-256. [CrossRef]

42. Lim, D.-H.; Wilcox, J. Dft-based study on oxygen adsorption on defective graphene-supported Pt nanoparticles. J. Phys. Chem. C 2011, 115, 22742-22747. [CrossRef] 
43. Liu, X.; Li, L.; Meng, C.; Han, Y. Palladium nanoparticles/defective graphene composites as oxygen reduction electrocatalysts: A first-principles study. J. Phys. Chem. C 2012, 116, 2710-2719. [CrossRef]

44. Kalantar-zadeh, K.; Ou, J.Z.; Daeneke, T.; Strano, M.S.; Pumera, M.; Gras, S.L. Two-dimensional transition metal dichalcogenides in biosystems. Adv. Funct. Mater. 2015, 25, 5086-5099. [CrossRef]

45. Alsaif, M.M.Y.A.; Chrimes, A.F.; Daeneke, T.; Balendhran, S.; Bellisario, D.O.; Son, Y.; Field, M.R.; Zhang, W.; Nili, H.; Nguyen, E.P. High-performance field effect transistors using electronic inks of 2d molybdenum oxide nanoflakes. Adv. Funct. Mater. 2016, 26, 91-100. [CrossRef]

46. Babaei, A.; Garrett, D.J.; Downard, A.J. Selective simultaneous determination of paracetamol and uric acid using a glassy carbon electrode modified with multiwalled carbon nanotube/chitosan composite. Electroanalysis 2011, 23, 417-423. [CrossRef]

47. Fu, L.; Lai, G.; Yu, A. Preparation of $\beta$-cyclodextrin functionalized reduced graphene oxide: Application for electrochemical determination of paracetamol. RSC Adv. 2015, 5, 76973-76978. [CrossRef]

48. Tefera, M.; Geto, A.; Tessema, M.; Admassie, S. Simultaneous determination of caffeine and paracetamol by square wave voltammetry at poly(4-amino-3-hydroxynaphthalene sulfonic acid)-modified glassy carbon electrode. Food Chem. 2016, 210, 156-162. [CrossRef] [PubMed]

49. Baccarin, M.; Santos, F.A.; Vicentini, F.C.; Zucolotto, V.; Janegitz, B.C.; Fatibello-Filho, O. Electrochemical sensor based on reduced graphene oxide/carbon black/chitosan composite for the simultaneous determination of dopamine and paracetamol concentrations in urine samples. J. Electroanal. Chem. 2017, 799, 436-443. [CrossRef]

50. Okoth, O.K.; Yan, K.; Liu, L.; Zhang, J. Simultaneous electrochemical determination of paracetamol and diclofenac based on poly(diallyldimethylammonium chloride) functionalized graphene. Electroanalysis 2016, 28, 76-82. [CrossRef]

51. Mao, A.; Li, H.; Jin, D.; Yu, L.; Hu, X. Fabrication of electrochemical sensor for paracetamol based on multi-walled carbon nanotubes and chitosan-copper complex by self-assembly technique. Talanta 2015, 144, 252-257. [CrossRef] [PubMed]

52. Tanuja, S.B.; Kumara Swamy, B.E.; Pai, K.V. Electrochemical determination of paracetamol in presence of folic acid at nevirapine modified carbon paste electrode: A cyclic voltammetric study. J. Electroanal. Chem. 2017, 798, 17-23. [CrossRef] 